\title{
E SE JÓ NÃO SE ARREPENDEU? A TRADUÇÃO DE JÓ 42,6
}

\author{
Osvaldo Luiz Ribeiro 1 \\ 1-Faculdade Unida de Vitória, Vitória, Espírito Santo, Brasil
}

\begin{abstract}
Resumo: O artigo avalia se a tradução que Jack Miles postula para Jó 42, 6 deve ser considerada melhor do que a tradução tradicional. Nos termos das traduções tradicionais de Jó 42,6, Jó se arrepende e se retrata de suas palavras, ao passo que, nos termos da tradução de Jack Miles, Jó não se arrepende nem se retrata, e, diante da manifestação de um deus que ele descobre como insensível, o personagem exprime profunda pena pelo "barro mortal". Com base no texto hebraico de Jó 42,6, o artigo avalia que, em termos gramaticais, tanto a tradução tradicional quanto a de Miles são adequadas, e concluir que a de Miles é preferível em relação à tradicional porque ela funciona melhor em termos de coerência com a estratégia narrativa do Livro de Jó.
\end{abstract}

Palavras-chave: Jó; Livro de Jó; Jó 42,6; Jack Miles; Tradução

\section{WHAT IF JOB DIDN'T REPENT? ON THE TRANSLATION OF JOB 42,6}

\begin{abstract}
The article assesses whether the translation that Jack Miles postulates for Job 42:6 should be considered better than the traditional translation. In terms of the traditional translations of Job 42:6, Job repents and retracts, whereas, in terms of Jack Miles' translation, Job does not repent or retract, and, in the face of the manifestation of a god who he finds out how insensitive, the character expresses deep pity for the "mortal clay". Based on the Hebrew text of Job 42:6, the article assesses that, in grammatical terms, both traditional and Miles' translations are adequate, and conclude that Miles' translation is preferable over the traditional one because it works better in terms of consistency with the narrative strategy of the Book of Job.
\end{abstract}

Keywords: Job; Book of Job; Job 42:6, Jack Miles; Translation 


\section{O alegado arrependimento de Jó}

Poucas histórias da Bíblia são tão conhecidas quanto a de Jó. Mas, advirta-se, a de Jó conforme contada pela tradição e mais concentrada na "história em prosa" (Terrien 7). Em termos os mais simplificados possíveis, trata-se da história de um homem a quem a divindade permite sobrevir uma série de mazelas, a ponto de o levar a clamar por consolo e a murmurar por justiça, clamores e murmurações interrompidos apenas pela manifestação fantástica da divindade, diante da qual - como quer a referida tradição, com quase absoluta unanimidade - Jó retrata-se, arrependido por não ter posto a mão à boca durante seu lancinante sofrimento: "ele oferece a resposta da fé pura à graça pura" (Terrien 7).

A despeito de suas lamentações e murmurações, o fenômeno de recepção da história não se furtou a cunhar, a partir dela, a expressão "paciência de Jó", articulada tão cedo quanto a redação de Tiago 5,11: "ouvistes da paciência de Jó" (Almeida 219-220). Não é que todos cheguem a uma conclusão tão radical quanto aquela que considera que "the term 'patience of Job' is a misnomer since Job is constantly protesting, and is actually impatient" (Lowrey 3 ), mas uma rápida pesquisa na internet a partir das chaves "paciência de Jó" ou "patience of Job" revelará que a despeito de Tiago e de sua longa tradição, não é sem surpresa que a fórmula se popularizou, já que, a rigor, é tão somente no final da longa narrativa que Jó, sempre segundo quer a tradição, recolhe-se e suspende suas imprecações: "in the end [...] Job admits that was wrong" (Ginsberg 111). Exatamente: no fim... E isso também porque "this is the juridical level at which man challenges God to a legal contest - and loses" (Loader 29). É "no fim" que Jó perde e é no fim que Jó se arrepende, e segundo se diz, "queda finalmente apaciguado y sereno" (Llano 11). Mas até lá, até que perca o desafio e se arrependa de suas palavras, se esse foi realmente o caso, o que efetivamente se ouve é a série de protestos de sua condição de inocente e de lamentos pelo sofrimento que incompreensivelmente tem de suportar: "o poeta de Jó poria a questão: 'há inocentes que 
sofrem?'. E responderia afirmativamente" (Terrien 7). Registrese, ainda, que o motivo do sofrimento do inocente, sofrimento esse dificilmente não imputável em alguma medida à própria divindade, provocou intenso e compreensível interesse no contexto pós-Holocausto (Kalman 328-330), e mesmo um autor que trata de tema tão sensível não se furta a aceitar que "Job patiently bore his suffering" (Kalman 5).

O referido arrependimento de Jó consubstanciar-se-ia em um verso de alegada clareza - Jó 42,6, do qual, a título de ilustração, se transcrevem alguns exemplos vernaculares, sem que se possam identificar divergências notáveis nas versões em outras línguas ${ }^{1}$ : "por isso, retrato-me e faço penitência no pó e na cinza" (Stadelmann 941); "também, por isso, tenho horror de mim e retrato-me no pó e na cinza" (TEB); "pelo que me abomino, e me arrependo no pó e na cinza" (Almeida, 469); "por isso me retrato e me arrependo, lançando pó e cinza sobre mim” (Alonso-Schökel, Bíblia do Peregrino,1.145); "portanto, detesto [a mim mesmo] e me arrependo no pó e na cinza” (Stern 1.049). Como querem as versões, retratação e arrependimento encerram os pronunciamentos de Jó.

É curioso que se tenha de explicar a razão pela qual um personagem ganhou reputação inclusive bíblica de ser paciente. A caracterização deveria ser imediata. Todavia, o comportamento do próprio personagem justifica que, diante da expressão tradicional "paciência de Jó", se tenha de apresentar alguma explicação. O comportamento de Jó e a estratégia narrativa da obra promoveram intenso debate nos séculos XIX e XX a respeito do caráter retórico da obra (Dell 1-4), havendo quem já em meados do século XIX asseverasse a natureza da narrativa como um protesto em face das teologias ortodoxas a respeito da divindade (Dell $44^{2}$ ). No entanto,

\footnotetext{
${ }^{1}$ Para a confirmação do declarado, uma série de versões internacionais da Bíblia, logo, de Jó 42, 6 pode ser consultada no endereço < https://www.biblestudytools. com/bible-versions/ $>$.

${ }^{2}$ A autora refere-se a $\mathrm{H}$. Heine, que teria assinalado a natureza radical e questionadora do livro em questão. A autora chegou a Heine por força de indicação de John Day a respeito de um artigo de 1965. Aqui, não se teve acesso nem ao
} 
ainda que a discussão seja exatamente o caráter teológico/psicológico do personagem, e mesmo ainda diante do notório constrangimento temático, didaticamente plasmado no título da composição - "Job the patient and Job the impatient" - a conclusão finda desaguando na mesma foz tradicional: "in the end [...] Job admits that was wrong in [...] this demand" (Ginzberg 111). O constrangimento da estrutura narrativa e das intermináveis murmurações de Jó não logra efetivo sucesso em contornar a força da tradição. Pelo contrário, assume-se que no conjunto dos discursos de Jó abundam "tonterías" (Gallazzi 39), e recente análise retórica da obra concluiu que "el discurso de Jehová parece ser muy contundente, al punto que lleva a Job a confesar su ignorancia. Dice que está arrepentido y que desea ser enseñado. [...] Jehová [...] al final le restaura completamente" (Martínez 94). Eventualmente seria pertinente considerar que, no final das contas, tanto o enredo quanto a extensão da narrativa das dores de Jó operem estrategicamente no sentido de assentar teologicamente "the mystic value of human suffering" (Parente 213) ou o caminho para um profundo "knowledge of God (Abangiba 89 e passim). Ou haveria alguma explicação menos teologicamente comprometida, uma explicação que coadunasse com a percepção de que, durante toda a longa narrativa, "Job expresa sus lamentos, sus dudas, pero sobre todo, su indignación. Porque de acuerdo con el largo desarrollo poético Job exige una explicación a Yahveh, y su tono no es de sumisión sino de desafio" (Cabrera 161)?

\section{Jack Miles e a contestação da tradução de Jó 42,6}

No que diz respeito à interpretação do Livro de Jó, não há acontecimento mais relevante do que a publicação das considerações de

artigo nem ao próprio Heine, mas se transcreve ipsis litteris a referência tal qual apresentada por Dell: “H. Heine in 'Spältere Note. In März 1854', a note to his 'Ludwig Marcus. Denkworte. Geschiereben zu Paris, den 22 April 1844' Quoted in full by F Ellermeier, 1965 (p 93), $c f$. Introduction p 1” (Dell 44). 
Jack Miles a respeito do que considera um problema de tradução em Jó 42,6. Naturalmente que esta é uma frase de efeito, mas é possível sustentá-la sem constrangimento. Trata-se da discussão constante no capítulo reservado a Jó na obra "God, a biography" (Milles God. A Biografy; Deus. Uma Biografia) ${ }^{3}$. No campo exegético-teológico, repercussões das considerações de Miles são praticamente inexistentes. Mesmo em ambientes mais disciplinarmente diversificados, quando determinada obra menciona o romance de Miles, ou se trata de mera menção da obra literária, sem qualquer consequência (Brueggemann), ou até se consideram aspectos dos comentários do romancista, mas absolutamente nada se fala sobre a correção da tradução de Jó 42, 6 (Maria 34-49), que Miles alega ser necessária. Quando se obtém algum êxito em localizar algum comentário especificamente sobre a tradução que Miles propõe para Jó 42,6, o resultado é este:

Miles's treatment of Job is a masterpiece of perverse hermeneutics [...]. By retranslating Job 42:1-6 (against all standard translations), Miles claims that Job really wins his argument with God! Instead of repenting of his accusations against God, Job simply says that he has said his piece and can say no more (Groothuis 3).

A despeito da potente carga teológico-ideológica da resenha de Groothuis, sua declaração quanto à tradução que Miles postula para Jó 42,6 posicionar-se "against all standard translations" (Groothuis 3) é correta. No entanto, no contexto da citação, tratase de um argumento contábil e de autoridade. $\mathrm{O}$ fato de a tradução que Miles postula, que, a seu ver, espelha melhor a ideia original da narrativa, distanciar-se do conjunto das tradições tradicionais não determina previamente o fato de que sua tradução - então -

\footnotetext{
${ }^{3}$ Para detalhes, $c f$. Ribeiro, 2018, em relação ao que o presente artigo poderia ser considerado um diálogo crítico.
} 
esteja errada. Nem mesmo que esteja certa. Trata-se de um dado que precisa ser analisado.

Nesse sentido, convém verificar a tradução que Miles postula para Jó 42, 6, abaixo transcrita em sua versão original, em inglês, e na corrente tradução brasileira daquela versão, no conjunto de Jó 42,1-6:

Tabela 1: Jó 42,1-6 segundo a tradução de Jack Miles

Then Job answered the Lord:

"You know you can do anything.

Nothing can stop you.

You ask: 'Who is this ignorant muddler?'

Well, I said more than I knew, wonders quite beyond me.

'You listen, and I'll talk,' you say.

'I'll question you, and you tell me.'

Word of you had reached my ears, but now that my eyes have seen you, I shudder with sorrow for mortal clay"

(Miles, God. A Biografy: 215).
Então, Jó respondeu ao Senhor:

"Sabes que tudo podes.

Nada o pode deter.

Perguntas: 'Quem é esse desordeiro ignorante?'.

Bem, falei mais do que eu sabia, maravilhas além do meu alcance.

'Tu ouves, eu falarei', dizes, 'eu perguntarei e tu responderás.'

Ouvira falar de ti, mas agora que meus olhos o viram, estremeço de pena pelo barro mortal"

(Miles, Deus. Uma Biografia: 407).

Fonte: Jack Miles

"I shudder with sorrow for mortal clay"/“estremeço de pena pelo barro mortal” é a tradução que Jack Miles faz de Jó 42,6. No contexto, transforma-se radicalmente a recepção tradicional da resposta de Jó à apresentação apoteótica da divindade: "ouvira falar de ti, mas agora que meus olhos o viram, estremeço de pena pelo barro mortal". O efeito da tradução de Miles estabelece um sentido não apenas novo em relação à recepção tradicional, mas radicalmente oposto. $\mathrm{O}$ protesto de inocência que Jó fazia à divindade devia-se ao fato de ele ter ouvido falar de sua justiça, de sorte que lhe parecia pertinente recorrer ao seu tribunal. Todavia, após a manifestação insensível da divindade, Jó se dá conta de que todos os seus protestos são inúteis, porque a divindade não tem ouvidos bem dispostos. Uma vez que 
Jó entende representar em sua própria pele potencialmente a vida de qualquer pessoa, e dado que ele pode suceder a qualquer um, sua conclusão não poderia ser outra: "estremeço de pena pelo barro mortal". Pobre do homem, se a divindade é quem se revelou ser...

É a proposta de tradução de Miles para Jó 42,6 o acontecimento mais importante da história da recepção dessa narrativa, desde pelo menos sua recepção no ambiente judaico-helênico, sua tradução do hebraico para o grego da LXX, a recepção da obra no cânon judaicocristão e a longa recepção tradicional cristã. E isso pelo simples fato de que a narrativa se transforma radicalmente se Miles tiver razão.

Nesse sentido, a tarefa que aqui se assume é verificar criticamente se a tradução de Miles pode ser tecnicamente sustentada.

\section{מאס na Bíblia Hebraica}

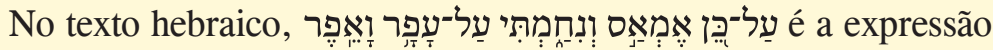
de Jó 42,6. Para a avaliação crítica da tradução de Miles, deve-se avaliar o comportamento sintático-gramatical dos verbos que a constituem (נחם especificamente sua predicação e regência, bem

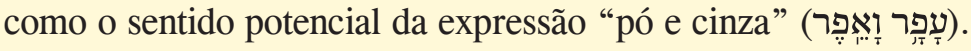

A raiz מאס ocorre em 69 versos na Bíblia Hebraica, podendo atualizar-se em dois casos sintáticos principais. Pode conjugar-se em regime de predicação direta, caso da maioria esmagadora das ocorrências, e pode conjugar-se muito raramente sem predicação. Nos casos de predicação direta, a raiz pode reger-se tanto por preposição quanto pela partícula indicativa de objeto direto (يֵ). Em Jó 42,6, a raiz atualiza-se sem predicação, e constitui um dos dois casos desse tipo na Bíblia Hebraica, ambos em Jó $(36,5$ e 42,6).

A despeito de atualizarem-se nos três blocos constitutivos da Bíblia Hebraica (Torá, Profetas e Escritos), os casos de predicação direta, com regência da preposição podem ser ilustrados, por exemplo,

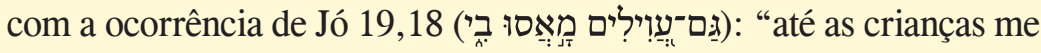

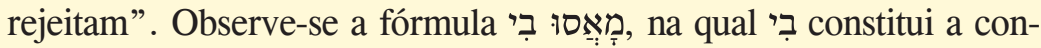
junção da preposição com o pronome pessoal, que, nesse caso, assu- 
me a função de objeto direto: "rejeitaram-me" ou "me rejeitaram". A despeito da regência da preposição, trata-se de predicação direta.

Ainda se atualizando na forma de predicação direta, a raiz pode ser empregada em construções sem qualquer cognitivo regencial ou, alternativamente, com o uso da partícula indicativa de objeto direto (אی). Um exemplo do primeiro caso encontra-se em Jó 31,13

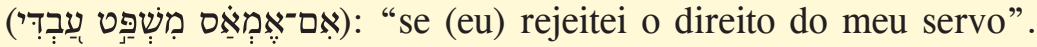
"O direito do meu servo" constitui objeto direto de "se eu rejeitei", e é introduzido sem qualquer conectivo, seja a preposição seja a partícula indicativa de objeto direito. Quanto ao segundo caso, não há ocorrências em Jó, mas pode-se apresentar como exemplo Nm

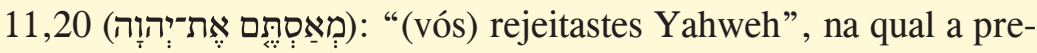
dicação direta se constrói por meio do conectivo אֵת.

Nenhum dos casos exemplificados acima ilustram a ocorrência de Jó 42,6. Como seu viu, há apenas dois casos de uso da raiz em regime

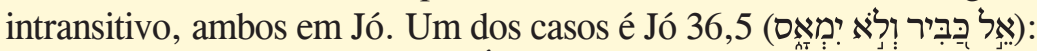
“El é grande, e não 'rejeita'”. É verdade que as versões comumente traduzem a passagem mais ou menos assim: "Deus é mui grande, mas

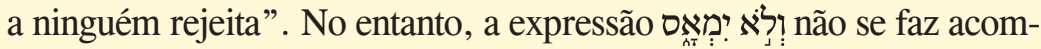
panhar de objeto ou predicativo. Por sua conta e risco, os tradutores introduzem a expressão "a ninguém" para, a seu modo, darem sentido à frase. Todavia, o texto hebraico simplesmente diz "El [...] não 'rejeita'". O verbo é intransitivo. No caso da segunda ocorrência, Jó 42,6 , o verbo igualmente se atualiza em regime intransitivo. Seja qual for o sentido que se vai conceder à raiz, não há qualquer tipo de pre-

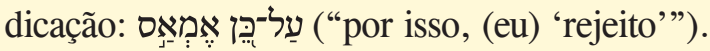

Identificado o regime sintático da atualização da raiz em Jó 42,6 , resta avaliar o sentido com que ali se expressa. Postula-se que, em termos gerais, a raiz signifique "to refuse, reject" ("recusar, rejeitar”) (Koehler \& Baumgartner 540). Para Jó 42,6, todavia, postula-se um sentido derivado: "rejeitar o que se disse anteriormente, revogar ("revoke"). O sentido aplicado à raiz, nesse caso, justifica-se por meio de dois pressupostos: a) Jó 42,6 constitui uma declaração de arrependimento do personagem, e b) a atitude de arrependimento transforma-se em declaração de retratação 
do que anteriormente Jó havia murmurado e dito. Talvez se possa considerar que a proposta de Koehler e Baumgartner tenha sido recepcionada favoravelmente por Schökel, que anota: "retratar-se Jó 42,6 = נחם arrepender-se" (Schökel 352).

Clines oferece maior leque de possibilidades para a tradução da raiz (Cline 120-121), mas, especificamente para Jó 42,6, sua proposta é "eu aceito e me arrependo no pó e nas cinzas" ("I accept and repent upon dust and ashes") (Cline 121). "Aceito" traduziria a raiz מאס. Koehler e Baumgartner, de um lado, e Clientes, de outro, concordam num ponto: Jó se arrepende. No entanto, no que diz respeito à tradução da raiz, o primeiro sugere que a referência seja ao que Jó falara, ele rejeita o que falara e se retrata do que dissera, ao passo que o segundo considera que a referência seja às palavras de Yahweh, ele aceita as palavras de Yahweh e, por isso, de arrepende de sua atitude. "Rejeitar" e "aceitar": estamos em terreno movediço aqui. Ainda que aceitar as palavras da divindade implique em necessariamente rejeitar as próprias, convém atentar para o fato de que se está decidindo tanto uma quanto outra atitude com base na tradução da raiz מאס, e o risco de se cair em um círculo vicioso que contamine o processo hermenêutico é sempre um risco. Já se leu neste periódico que, entre hermenêutica e poética, "deve-se escolher um ou outro" (Oseke-Depré 474).

\section{נחם na Bíblia Hebraica}

A tradução da raiz נחם em Jó 42, 6 constitui também um problema hermenêutico. Conquanto nesse campo pode-se considerar mais recomendável focar-se na tradução do significado, e não da palavra (Stefanink \& Bălăcescu 23) ${ }^{4}$, é o sentido com que a palavra foi empregada na passagem que estabelece os limites não criativos dentro dos quais a tradução se deveria operar. Não se está longe da

4 "Because it is the closest thing to an ideal translational practice which focuses on translating meanings, not words".

Cad. Trad., Florianópolis, v. 41, n⿳2 2 p. 137-158, mai-ago, 2021. 
questão discutida por Comellas a respeito da disputa entre autoria e tradução, que se poderia ilustrar com a seguinte citação: “ou a tradução pensa demais em si mesma (e quem traduz quer deixar nela um cunho pessoal) ou pensa demais no leitor (na fisionomia da língua de chegada, no "grande estilo"), mas nunca pensa o suficiente no autor" (Comellas 15). Para se dizer o mesmo, mas de outro modo, "traduttore-traditore: \#sóquenão" (D’Angelo 158). Sendo o caso de a palavra comportar vários sentidos diferentes, a decisão pelo sentido que se vai aplicar à tradução dessa palavra é uma decisão que pode desdobrar-se a partir de diferentes interesses, com maior ou menor lugar para a criatividade, a subjetividade e as rotinas programáticas de releitura e recepção. No que aqui interessa, a questão é com qual dos seus sentidos potenciais o autor de Jó 42,6 utilizou a raiz נחם.

A lista de potenciais sentidos da raiz apresentados por Schökel é grande o suficiente para recomendar uma transcrição: “arrependerse, doer-se, compungir-se, deplorar, lamentar, sentir pesar; consolar-se, aliviar-se, acalmar-se, aplacar-se; compadecer-se, condoerse, apiedar-se, sentir pena, compaixão, piedade" (Alonso-Schökel, Dicionário bíblico hebraico-português, 429). Deve-se anotar que os demais dicionários anteriormente citados confirmam a amplitude de sentidos potenciais que a raiz comporta (Clines 663-665; Koehler \& Baumgartner 688-689).

Voltando ao dicionário de Alonso-Schökel, na mesma rubrica, o conjunto citado é reunido em torno de três sentidos básicos: a) arrepender-se, b) compadecer-se e c) consolar-se (Alonso-Schökel, Dicionário bíblico hebraico-português, 429-430). A simples constatação de que a raiz comporta o sentido de "arrepender-se", com o qual tradicionalmente a raiz é traduzida nas versões de Jó e nos comentários, também os exegéticos, ao mesmo tempo em que comporta o sentido de "compadecer-se", "ter pena de" sugere precaução, quanto mais a raiz anterior ser tratada por um dicionário como "rejeitar" e, pelo outro, "aceitar". Caso se considere aproximar o sentido de "consolar-se" e "apiedar-se" do campo antônimo de 
"vingar-se", então também se poderia atualizar a raiz נחם por meio de termos que comportam sentidos antônimos. Os três dicionários citados são unânimes em atestar o sentido de "vingar-se" para a raiz que, ao mesmo tempo, pode significar "ter compaixão" (Alonso-Schökel, Dicionário bíblico hebraico-português, 430; Clines 664; Koehler \& Baumgartner 689).

Em Jó 42, 6 há duas raízes que podem ser atualizadas alternativamente por antônimos: "rejeitar/aceitar" e "vingar-se/compadecer-se". Quanta prudência se nos recomenda tal informação? No mínimo aquela que se poderia sopesar da seguinte declaração a respeito de Jó 42,6:

his verse has been subject to various interpretations, depending on one's orientation. This has been occasioned by the difficult and ambiguous nature of the verse. The difficulty and ambiguity of this verse is a reflection of the difficulty and ambiguity of the book as a whole (Abangiba 48).

\section{na Bíblia Hebraica}

Em Jó 42,6, a expressão em hebraico imediatamente acima é tradicionalmente traduzida como constituindo um adjunto adverbial de lugar e/ou modo, significando, em conjunção com o verbo que, então, circunstanciaria, uma atitude de profunda contrição e radical arrependimento: "eu me arrependo no pó e na cinza", para transcrever uma das mais tradicionais versões no vernáculo.

$\mathrm{Na}$ forma como se encontra grafada em Jó 42,6, a frase cuja tradução foi exemplificada acima encontra-se apenas nesse verso. Mesmo se recortarmos da frase a expressão, acrescida apenas da preposição com que é regida sintaticamente (עַל־עָפָר וָאֵפֶר), apenas em Jó 42,6 ela poderia ser identificada. Ocorre, no entanto, que exatamente como se encontra em Jó 42,6, mas sem a companhia do verbo ali empregado e igualmente sem a preposição que ali a rege, 
a expressão é empregada em uma passagem da Bíblia Hebraica que guarda importantes implicações para Jó 42,6. Trata-se de Gn 18,27. No contexto, trata-se de diálogo entre Abraão e a divindade, por meio do qual Abraão tenta demovê-la da destruição de Sodoma. Precavido de toda humildade retórica, Abrão assevera à divindade que reconhece seu próprio lugar de homem (comparativamente ao da divindade), mas, a despeito disso, ousa, para interceder-lhe pedir a favor dos justos, dirigir-se a quem ele reconhece como incomparavelmente superior. A fórmula que Abraão usa para expressar a ideia de que tem consciência de ser incomparavelmente pequeno em relação à divindade é a seguinte:

Tabela 2: Gênesis 18,27

\begin{tabular}{|c|c|c|}
\hline 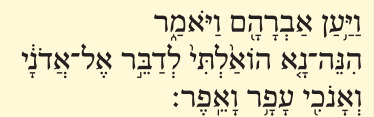 & $\begin{array}{c}\text { Gn } \\
18,27\end{array}$ & $\begin{array}{l}\text { "E acrescentou Abraão, dizendo: } \\
\text { "eis que me atrevo a falar ao Senhor, } \\
\text { ainda que eu seja pó e cinza'". }\end{array}$ \\
\hline
\end{tabular}

Fonte: tradução do pesquisador

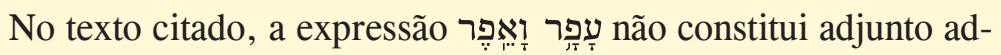
verbial de modo e/ou lugar, mas expressa-se na forma de uma metáfora que faz as vezes de predicativo do sujeito. Ainda que, no contexto sintático, deva ser correto traduzir-se "ainda que eu seja

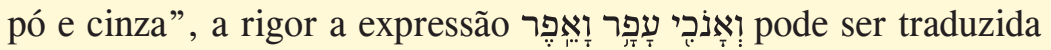
como "eu sou pó e cinza". Miles transforma "pó e cinza" em "mortal clay"/"barro mortal", e sua tradução - "estremeço de pena do barro mortal" - está justificada.

Uma última questão deve ser tratada - a regência preposicional do verbo נחם em Jó 42,6. O texto hebraico é Aí se flagra, na língua fonte, a regência preposicional do verbo - עַל עפר rege a raiz נחם. A regência preposicional imporia à raiz um sentido restrito? Bem, na Bíblia hebraica, podem-se identificar atualizações da mesma raiz com diferentes sentidos, todos regidos igualmente pela preposição עַ. Para 0

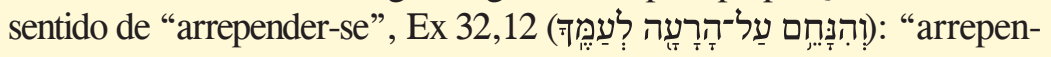


de-te do mal contra o teu povo". Para o sentido de "consolar-se", 2

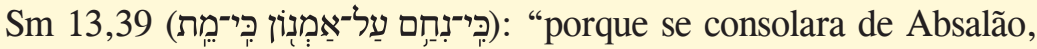
que morrera". Para o sentido de "compadecer-se", Sl 90,13 (

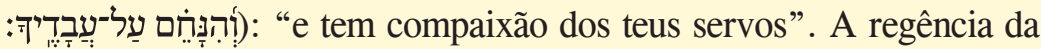
preposição não determina restritamente o sentido do verbo, e, em tese, por esse critério, a raiz poderia ser atualizada tanto como "arrepender-se", como com "consolar-se" ou "compadecer-se".

Comparativamente a Gn 18,27, em Jó 42,6 "pó e cinza" constituiria uma referência metafórica à condição do homem judeu: o Senhor é o Senhor, e o judeu não é mais que “pó e cinza”. Não é que o judeu - o homem, se decidirmos inflacionar antropologicamente a declaração - esteja no pó e na cinza. Ele mesmo, o homem é "pó e cinza". Seria o caso de a expressão suportar igualmente tal atualização semântico-metafórica em Jó 42,6?

\section{Avaliação crítica da tradução de Jó 42,6 de Jack Miles}

A tradução que Jack Miles sugeriu para Jó 42, 6 é do tipo que se poderia incluir no rol das traduções de equivalência dinâmica (Kerr 1-2). No quadro abaixo, pode-se observar como ocorre a versão da língua fonte para a língua inglesa (e daí para a língua portuguesa).

Tabela 3: Jó 42,6 segundo Jack Miles

\begin{tabular}{|c|c|}
\hline 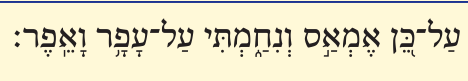 & $\begin{array}{l}\text { "I shudder with sorrow for mortal clay" } \\
\text { / "estremeço de pena pelo barro mortal" }\end{array}$ \\
\hline
\end{tabular}

Fonte: Miles, God. A Biografy: 215.

A despeito da configuração dinâmica do modelo de tradução, avalia-se se, no todo e em cada uma de suas partes constitutivas, é possível chegar à tradução "I shudder with sorrow for mortal clay" partindo-se do texto hebraico. Em termos gramaticais, a tradução de Jack Miles funciona como proposta de tradução para Jó 42, 6. 
É possível expressar algum ressentimento pelo fato de Miles ter convertido dois verbos hebraicos em apenas uma expressão verbal em inglês. Em hebraico, constatam-se as raízes acima analisadas מאס e נחם. Miles converte o conjunto em apenas uma expressão verbal: "I shudder with sorrow"/“estremeço de pena". O critério dinâmico permite o processo, e, para todos os efeitos, ainda que se possa considerar que o resultado seja mais pobre do que o conjunto na língua fonte, a ideia de que a conjunção das duas raízes possa exprimir a ideia de um profundo sentimento de pena em relação ao "barro mortal" se justifica. No contexto da interpretação de Miles, a primeira raiz poderia comportar a ideia de que Jó "desiste" (מאס) de encaminhar suas queixas à divindade, dado ter acabado de descobrir que se trata de uma potência absolutamente insensível, ao passo que a segunda raiz (נחם) exprimira então a ideia de que, ciente da insensibilidade divina, o personagem experimenta um profundo pesar pelo "barro mortal". "Estremeço de pena (do barro mortal)" praticamente expressa a ideia que a segunda raiz poderia sozinha suportar, de sorte que , como se disse, se poderia considerar que Miles empobreceu a declaração de Jó potencializada pela língua fonte, mas não que "perverteu a hermenêutica", a despeito de essa ter sido a avaliação de seu resenhista acima citado (Groothuis 3).

Como se viu, a atualização verbal de Jó 42, 6 não possui predicação, e é um dos dois únicos casos da Bíblia Hebraica, ao lado de Jó 36,5. A ação verbal se expressa intransitivamente. O fluxo narrativo deve ser ligado à clausula temporal anterior, que se resume no fato de Jó ter contemplado a apoteose teológica divina, diante da qual ele se dá conta de que não há mais o que dizer, posto que não há quem esteja disposto realmente a ouvir. Nesse sentido, a atualização intransitiva de סאמ poderia significar algo como "eu desisto (de continuar falando)", mas não no sentido que a tradição tem aplicado, como se Jó desistisse porque se desse conta das "tonterías" (Gallazzi 39) que se diz ter falado, mas, ao contrário, justamente pelo fato de que finalmente percebeu que falara sem que a divindade lhe desse a mínima atenção. Assim, na sequência, Jó avança para aplicar aos seus pares de dor a conclusão dessa sua 
descoberta: "pobres companheiros de dor". A tradução de Miles condensa esse momento em sua última expressão: "estremeço de pena do barro mortal".

"Mortal clay"/"barro mortal" é a forma como Miles traduz a

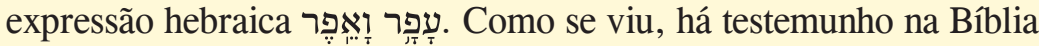
Hebraica do uso dessa precisa expressão com esse exato sentido. Em

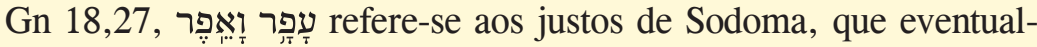
mente a divindade preservaria. Em Jó 42,6, a mesma expressão funciona adequadamente como proposta para referir-se a cada sofredor que se vê vítima da insensibilidade divina. Considerando-se que a atualização verbal da raiz נחם se faz reger pela preposição עַל e, como se viu, haver testemunho na Bíblia Hebraica da atualização dessa raiz, regida pela mesma preposição, com o sentido de "ter compaixão de", "apiedar-se de", "ter pena de", deve-se forçosamente concluir que, no que diz respeito à gramática e à sintaxe, a

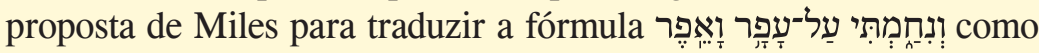
"tenho pena do barro mortal" se justifica plenamente.

\section{Jó se arrepende ou Jó não se arrepende?}

$O$ fato de que a tradução de Miles deve ser assumida como gramaticalmente e sintaticamente adequada não significa, necessarian mente, que ela expresse a ideia original de Jó 42,6. Por mais antagônicas que sejam, tanto a tradução tradicional quanto a de Miles são gramaticalmente possíveis. Na Bíblia Hebraica, esse não é um

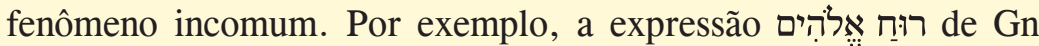
1,2 pode ser adequadamente traduzida tanto por "Espírito de Deus" quanto por "vento de Deus" ou "sopro de Deus", e as três atualizações podem ser encontradas, caso a caso, em diferentes versões da Bíblia que circulam no Brasil. As três formas são gramatical e sintaticamente possíveis. Casos assim - Gn 1,2 e Jó 42,6 - não se resolvem ao nível da gramática, conquanto, no caso de Jó 42,6, a questão gramatical seja importante, porque reações das do tipo de Groothuis, que precipitadamente aplica a Miles as palavras que a divindade di- 
rige a Jó ("God's words to Job are still pertinent: "who is this that darkens my counsel with words without knowledge?' [Groothuis 4]) precisam ser respondidas. No entanto, mesmo podendo asseverar ao resenhista de Miles que a operação exegética proposta é adequada, ainda assim não se resolve a questão do sentido original que se pretendeu dar a tão ambígua construção. O escritor original de Jó 42, 6 tinha em mente uma cena de arrependimento e retratação de Jó, ou, ao contrário, e como permite vislumbrar a tradução de Miles, aqui assumida, uma cena em que a representação divina com a qual se elabora a narrativa é radicalmente criticada, denunciando-a como portadora de insensibilidade extrema?

Por uma questão de espaço, deixemos de lado a questão da composição narrativa. De um lado, um Prólogo e um Epílogo (Jó 1,2; 42,7-17), em prosa, e de outro, um núcleo $(3,1-42,6)$, originalmente independentemente em relação à anterior (Terrien 18-35). Permaneçamos na órbita da questão da estratégia narrativa. O referido núcleo constitui-se de longa série de reclamações, protestos, lamentos, gritos mesmo, de Jó (3,1-37,24). A série de lamúrias e reivindicações de Jó é interrompida pela manifestação apoteótica da divindade $(38,1-41,34)$. O núcleo poético se encerra com seis versos por meio dos quais Jó reage à manifestação da divindade $(42,1-6)$.

Admitamos por um momento que os seis versos finais do núcleo poético devem significar arrependimento e retratação de Jó, mas, a título de argumento, alteremos o conteúdo do jogo. Digamos que Jó 3,1-42,6 tivesse por intenção interditar a determinado educando o uso de palavras de baixo calão. Para o fazer, o compositor escreve uma longa narrativa, na qual o personagem profere todas as palavras de baixo calão que a narrativa tem por interesse ensinar que não se devem usar. De Jó 3,1 até 37,24, por mais de 30 capítulos, uma narrativa que teria por intenção ensinar a não se falar palavras impróprias terá curiosamente colocado o educando em contato com palavras que eventualmente ele ainda sequer conhecia! No final das contas, o educando receberá um conjunto de palavras que, a despeito de estar sendo dito que ele não as pode proferir, ficarão 
em sua mente, e, fatalmente, ele há de se lembrar delas na primeira topada... Não parece uma estratégia muito eficiente.

Por outro lado, se imaginarmos que a narrativa pretendida, originalmente, não dar razão à divindade, mas criticar a série de argumentos que tanto ela quanto os amigos do desgraçado personagem instrumentalizariam, então faz sentido que a narrativa apresentasse um a um os argumentos tradicionais a respeito da teodiceia, fizesse Jó refutar individualmente e no conjunto todos eles, introduzir a manifestação insensibilíssima de uma divindade tomada pela megalomania teológica e, finalmente, assentar o golpe de cutelo: se a divindade é isso que se apresenta, esse colosso de insensibilidade, o que se há de dizer quanto a tudo que $e u$ disse é que é inútil dizê -lo, mas não porque o que eu disse são as razões de um louco, mas, ao contrário, porque a divindade é surda e arrogante, e, por causa disso, eu tenho pena do barro mortal.

Se a tradução de Miles for considera mais adequada ao conjunto da narrativa do que a tradução tradicional, então o núcleo poético do Livro de Jó tem sido lido de modo totalmente contrário a seu objetivo original, porque aquilo que originalmente constituiria uma crítica radical da teodiceia judaica transformar-se na defesa dessa mesma teologia.

\section{Conclusão}

Há pelo menos dois mil anos o livro de Jó é lido como a experiência de sofrimento, lamento e protesto de inocência e, finalmente, retratação e arrependimento de Jó, convertido então no modelo de comportamento diante da dor humana. A chave para essa interpretação repousa no relicário de um verso: Jó 42,6, amiúde traduzido mais ou menos como "eu me retrato e me arrependo no pó e na cinza".

Em 1996, Jack Miles sugeriu que, a despeito de possível em termos gramaticais, a mencionada tradução estivesse errada na perspectiva do sentido original do texto fonte. Propõe então que a tradução adequada seria "I shudder with sorrow for mortal 
clay"/“estremeço de pena pelo barro mortal”. Uma avaliação de cada palavra e da relação sintática de cada seção do verso na língua fonte revela que a proposta de Miles é adequada em termos gramaticais. No entanto, a tradução inverte radicalmente a atitude teológico-psicológica do personagem. Se a tradução de Miles for considerada redacionalmente correta - porque gramaticalmente correta ela o é -, então deve-se assumir que Jó não apenas não se arrepende, mas arrosta à divindade a acusação de que, dada a sua inamovível insensibilidade e arrogante megalomania teológica, o "barro mortal" está em desgraçada e penosa situação: "eu estremeço de pena do barro mortal".

Se as duas traduções são gramaticalmente possíveis, em termos de estratégia narrativa, a de Miles funciona melhor. Jó refuta todos os argumentos da teodiceia tradicional, para, finalmente, retratarse, ou Jó os refuta e, diante da insensibilidade divina, conclui que o "barro mortal" só pode ser merecedor de pena e dó, posto não passar de um brinquedo nas mãos de um deus sem coração? Estamos diante de um compositor que, para ensinar submissão teológica, perfila uma série de, nesse caso, repreensíveis e condenáveis atitudes e palavras de insubordinação teológica que conviria considerar inapropriadas ao bom fiel, ou, ao contrário, estamos diante de um compositor que, para revelar o absurdo da teodiceia judaíta tradicional, refuta um a um todos os argumentos de sua tradicional sustentação, contraditando-os todos por meio do personagem, para, no final, após manifestação tragicômica do deslumbramento insensibilíssimo de uma divindade perdida em si mesma, silenciar o desgraçado Jó, não sem antes assentar um fato bastante coerente com o motivo da peça e seu enredo: "eu te conhecia de ouvido, e por isso me dirigi insistentemente a ti, porque acreditava - tolo que eu fui! - que seria ouvido. Mas agora que os meus olhos te viram, eu desisto de falar, e "estremeço de pena do barro mortal". Uma peça conservadora, que assenta uma teologia conservadora, ou a mais crítica dentre todas as narrativas da Bíblia Hebraica? Certamente a tradução de $J o ́$ 42,6 não resolve a questão - mas, salvo melhor juízo, ela certamente a impõe. 


\section{Referências}

Abangiba, Amore Gregory. Experience of suffering as a way to a deeper knowledge of God. An Analysis of Job 42:1-6. A Thesis of Master of Art in Theology. Nairobi: Tangaza University College and University of Duquesne, 2014.

A Bíblia Sagrada. Testamento e Novo Testamento. Versão revisada da tradução de João Ferreira de Almeida. De acordo com os melhores textos em hebraico e grego. Rio de Janeiro: Imprensa Bíblia Brasileira, 1992.

Alonso-Schökel, Luís. Bíblia do Peregrino. Tradução do texto bíblico de Ivo Storniolo e José Bortolini. São Paulo: Loyola, 2002.

Alonso-Schökel, Luís. Dicionário bíblico hebraico-português. Tradução de Ivo Storniolo e José Bortolini. São Paulo: Paulus, 1997.

Brueggemann, Walter. Teologia do Antigo Testamento. Testemunho, disputa, defesa. São Paulo: Paulus; Santo André: Academia Cristã, 2014.

Cabrera, Isabel. "Kafka a través de Job, Job a través de Kafka". Topicos del Seminario. 22 (2009): 157-174. 29/01/2020 <http://www.scielo.org.mx/pdf/ tods/n22/n22a7.pdf >.

Clines, David J. A (Ed.). The dictionary of classical Hebrew. Volume V. Sheffield: Sheffield Academic Press, 2001.

Colares, Adriana Almeida. "Tradução e Hermenêutica". Cadernos de Tradução. v 39.3 (2019): 472-485. 28/01/2020. DOI: https://doi.org/10.5007/21757968.2019v39n3p472. Disponível em: https://periodicos.ufsc.br/index.php/ traducao/article/view/2175-7968.2019v39n3p472/40865.

Comellas, Pere. "Autoria contra tradução ou tradução contra autoria: Milan Kundera, Jorge Luís Borges e o fim do indivíduo". Cadernos de Tradução. 2.24 (2009): 9-30. 28/01/2020. DOI: https://doi.org/10.5007/2175-7968.2009v2n24p9. 
Disponível em: https://periodicos.ufsc.br/index.php/traducao/article/view/21757968.2009v2n24p9/12215.

D’Angelo, Biagio. "Traduttore-traditore: \#sóquenão. A intersemiose como desafio educativo das artes". Cadernos de Tradução. 36.3 (2016): 158173. 28/01/2020. DOI: https://doi.org/10.5007/2175-7968.2016v36n3p158. Disponível em: https://periodicos.ufsc.br/index.php/traducao/article/view/21757968.2016v36n3p158/32407.

Dell, Katharine J. The Book of Job as sceptical literature. Berlin e New York: Walter de Gruyter, 1991.

Gallazzi, Sandro. "El grito de Job y de su mujer". Revista de Interpretación Bíblica Latinoamericana. 52.3 (2005): 31-52.

Ginsberg, H. L. "Job the patient and Job the impatient". Anderson, G. W. et al (org). Suplements to Vetus Testamentum. 17 (1969): 88-11. 29/01/2020 < https:// tinyurl.com/r5h94sk $>$.

Groothuis, Douglas. A summary critique: God: a biography, by Jack Miles. Sem data. 29/01/2020<http://www.equip.org/PDF/DG119.pdf > .

Kalman, Jason. With friends like these. Turning points in the Jewish exegesis of the biblical Book of Job. Montreal: McGill University, 2005.

Kerr, Glen J. "Dynamic equivalence and its daughters. Placing Bible translation theories in their historical context". Journal of Translation. 7.1 (2011): 1-19. 29/01/2020 < https://tinyurl.com/umfb3p4>.

Koehler, Ludwig; Baumgartner, Walter. The Hebrew and Aramaic lexicon of the Old Testament. Study edition. Volume 1. Traduzido sob a supervisão de M. E. J. Richardson. London: Brill, 2001.

Llano, Ignacio Cabello. El Libro de Job e su recepción em el Cristianismo medieval. Perspectivas y reflexiones sobre el sufrimiento humano y el mal. Trabajo 
de Fin de Máster del Máster em Ciencias de las Religiones. Madrid: Universidad Complutense de Madrid, 2019.

Loader, J. A. “Job-answer or enigma?”. Old Testament Essays. 2.1 (1984): 1-38. 29/01/2020< <ttps://tinyurl.com/wuulsna >.

Lowrey, David H. Job behind the curtain. 29/01/2020 < https://tinyurl.com/ ukfybhg $>$.

Maria, Claudinei. "O pão da dor e o vinho da miséria”. O banquete da existência, de Jó a Brás Cubas. Dissertação (Mestrado). Campinas: Universidade Estadual de Campinas, 2007.

Martínez, Celestino Ayala. Análisis retórico del libro de Job. Tesis de Magister en Lingüística. Bogotá: Universidad Nacional de Colombia, 2014.

Miles, J. Deus. Uma biografia. São Paulo: Companhia das Letras, 2009.

Miles, J. God. A biography. New York: Vintage Books, 1996.

Parente, Pascal P. "The Book of Job. Reflections on the mystic value of human suffering”. The Catholic Biblical Quarterly. 8.2 (1946): 213-219. 29/01/2020 $<$ https://tinyurl.com/wzmvhca $>$.

Ribeiro, Osvaldo Luiz. “'Estremeço de pena pelo barro mortal’: Jack Miles e uma Introdução ao Livro de Jó”. Teoliterária. 8.16 (2018): 293-321. 31/01/2020 $<$ https://tinyurl.com/wb75nu2 $>$.

Stadelmann, Luiz Inácio. Jó. Em: A Bíblia de Jerusalém. São Paulo: Paulus, 1989.

Stefanink, Bernd; Bălăcescu, Ioana. "The hermeneutical approach in translate studies". Cadernos de Tradução. 37.3 (2017): 21-52. 28/01/2020 < https:// tinyurl.com/w67fqxo $>$. 
Stern, David H. Bíblia judaica completa. O Tanak [AT] e a B'rit Hadashah [NT]. Tradução do inglês para o português de Rogério Portella e Celso Eronides Fernandes. São Paulo: Vida, 2011.

TEB - Tradução Ecumênica da Bíblia. Sem indicação da tradução. São Paulo: Loyola, 1994.

Terrien, Samuel. Jó. São Paulo: Paulus, 1994.

Recebido em: 30/11/2020

Aceito em: 12/03/2021

Publicado em maio de 2021

Osvaldo Luiz Ribeiro. E-mail: osvaldo@fuv.edu.br. ORCID: https://orcid. org/0000-0003-2463-0093. 